\title{
The Effect of Concrete Topping Thickness on the Vibration Response of Prestressed and Precast Hollow Core Floor Systems
}

\author{
M. I. Rahimi ${ }^{1}$, N. H. Abd Ghafar ${ }^{2 *}$, Z. Ibrahim³ ${ }^{3}$ Z. M. Jaini' ${ }^{2}$ N. Z. Abd Aziz ${ }^{1}$, \\ N. E. Mat Gamadi ${ }^{1}$
}

${ }^{1}$ Faculty of Civil Engineering and Built Environment,

Universiti Tun Hussein Onn Malaysia, 86400 Parit Raja, Johor, MALAYSIA

${ }^{2}$ Jamilus Research Center,

Universiti Tun Hussein Onn Malaysia, 86400 Parit Raja, Johor, MALAYSIA

${ }^{3}$ Department of Civil Engineering, Faculty of Engineering,

University of Malaya, 50603 Kuala Lumpur, MALAYSIA

*Corresponding Author

DOI: https://doi.org/10.30880/ijie.2020.12.08.034

Received 13 March 2020; Accepted 16 May 2020; Available online 15 September 2020

\begin{abstract}
In the field of floor vibration, there is a need to consider several vibration parameters. Mass, stiffness, damping and frequency are the most common causes of excessive vibration to floor systems. However, there is a need for better understanding of vibration caused by the interaction between stiffness and added mass by concrete topping. This paper presents a vibration behaviour analysis on the effects of concrete topping on prestressed and precast hollow core floor (PPHCF) systems. Experimental modal analysis (EMA) was performed on a selected floor area in a four-storey office building by conducting an ambient test. From the EMA, the results were further verified using finite element analysis (FEA). During the FEA, numerical dynamic analysis was conducted with the implementation of the finite element model by increasing the topping thickness. For thickness ranging between $0 \mathrm{~mm}$ to $350 \mathrm{~mm}$ with an interval of $25 \mathrm{~mm}$, the optimum value of concrete topping thickness was $150 \mathrm{~mm}$. From the analysis, the behaviour of the floor systems with concrete toppings measuring lower than $150 \mathrm{~mm}$ thick was found to be dominated by mass whereas for concrete toppings measuring more than $150 \mathrm{~mm}$ thick, the behaviour of the floor system was found to be dominated by stiffness.
\end{abstract}

Keywords: Hollow core floor, vibration, experimental modal analysis, ambient vibration, concrete topping, lowfrequency floor

\section{Introduction}

Modern floors are renowned in using lightweight and long spans properties in the construction which often prone to serviceability issues, especially vibration, which is mostly influenced by stiffness and mass [3], [4], [11]. Floor vibration is usually caused by human activities conveyed through the floor from one place to another, such as walking, running and jumping. 
Low mass is currently desirable for most precast concrete floors. Prestressed and precast hollow core floors (PPHCF) are thick from 110mm to 500mm but hollow along its length [13], [14]. Hollow along the precast reduces the overall weight of the PPHCF. As floor mass is one of the components that contribute to vibration behaviour, it receives higher excitation from human activity, especially long-span precast floor systems. This PPHCF system is usually installed in multi-storey buildings, such as apartments, office buildings and shopping malls. The benefits of PPHCF include its ability to support heavy loads due to high strength and its long and clear spans. In addition, the voids along the span can be used for mechanical and electrical equipment [1]. However, its performance is not as ideal in terms of floor vibration.

The lightweight properties of PPHCF make it sensitive to any excitation forces ranging from $4 \mathrm{~Hz}$ to $10 \mathrm{~Hz}$ [5]. Fundamental natural frequency below $10 \mathrm{~Hz}$ may cause resonance interaction with humans [6]. At a state of high floor frequency, more than $10 \mathrm{~Hz}$ is preferable for the floor to resist excessive excitation. It is favourable for precast floors to be high in mass, in which the response is influenced by lower amplitude [4]. A typical long-span lightweight precast floor is mostly influenced by low mass and bending stiffness that leads to vibration.

Vibration behaviour also depends on the stiffness of floor systems; the rigidity of the floor affects its fundamental natural frequency. Increasing floor stiffness helps reduce excitation from human activities, which can cause an increase in natural frequency [7]. Therefore, high stiffness is preferable to achieve better vibration behaviour. On the other hand, floor systems with low stiffness might cause excessive vibration as they are more susceptible to deflection.

Stiffness combined with floor mass can have an influence on excitation caused by human activities. With added concrete topping which acts as an added composite mass, it may increase the percentage of risk of vibration to occur due to the domination between mass and stiffness. However, added concrete toppings with different mass and stiffness can cause natural frequencies to vary [3], [8], [9]. Concrete topping contributes to the increase in mass, but the stiffness between the precast concrete topping influences the excitation of the floor due to different concrete strength and materials.

In 2017 [15], the author had stated the result for the natural frequency of the precast had a different value for the precast with concrete topping and without concrete topping for the experimental result on $270 \mathrm{~mm}$ thick precast. The precast with topping seems had low natural frequency than without concrete topping from $6.82 \mathrm{~Hz}$ to $6.31 \mathrm{~Hz}$ with $50 \mathrm{~mm}$ added topping. Similar behaviour reported in [16], the finite element analysis (FEA) showed a decrease value in natural frequency on $183 \mathrm{~mm}$ precast with added $30 \mathrm{~mm}$ concrete topping from $7.4 \mathrm{~Hz}$ drop to $5.9 \mathrm{~Hz}$. Both studies in [15], [16] had mentioned both precast and concrete topping had different concrete strength. The pattern result showed the concrete topping is affected the natural frequency.

Thus, this paper aims to assess the effect of concrete topping thickness on the vibration behaviour of PPHCF. The research is divided into three phases. Phase 1 involves an experimental study on the prestressed and precast hollow core floor system, In Phase 2, validation using the finite element method (FEM) was conducted. Finally in phase 3, a parametric study on different concrete toppings of different sizes was carried out. The experimental research involved two bay areas in an office building with a dimension of $8100 \mathrm{~mm}$ x $8100 \mathrm{~mm}$ per bay. The data was collected by running an ambient test with 16 units of accelerometers to record acceleration data. The numerical result was processed via the Enhanced Frequency Domain Decomposition (EFDD) method using ARTeMIS software. The finite shell element model was developed and calibrated with the experimental results using SAP2000.

\subsection{Floor Detailing}

The four-storey building was constructed using a combination of precast and in-situ concrete flooring systems as shown in Fig. 1. PPHCF with C50 concrete strength was installed on the S335 I-beam. The 75 mm concrete topping was poured on the PPHCF to complete the flooring system. Due to a few constraints including limited space area, only certain floor systems were selected as illustrated in Fig. 1. The floor area consists of two bays with a dimension of $8100 \mathrm{~mm} \times 8100 \mathrm{~mm}$ per bay, as shown in Fig. 2. A floor bay consists of hollow core precast with a width of $1200 \mathrm{~mm}$ and a long span of $8000 \mathrm{~mm}$. The depth of PPHCF is $265 \mathrm{~mm}$ and the cross-section of the hollow core is illustrated in Fig. 3.

\subsection{Experimental Modal Analysis (EMA)}

The floor structure was experimentally determined through an ambient vibration test with 16 units of KS 48C high sensitivity accelerometers. The roving method was used as the limitation of the accelerometers for 91 points fully covered testing floor area. Seven sets of data were run with three reference points to record the acceleration data and one set of data involved thirteen moveable accelerometers, as shown in Fig. 4. The test duration for each set was 10 minutes with a $200 \mathrm{~Hz}$ sampling rate to measure $100 \mathrm{~Hz}$ of Nyquist frequency. The acceleration response data was converted to the Frequency Response Function (FRF) using additional acquisition parameters as mentioned in Table 1.

The FRF measurements were analysed using the EFDD modal analysis method to determine the vibration response for the floor. The analysis was run using the ARTeMIS software package by a peak picking method to determine the natural frequency, mode shape and damping ratio. The time data domain was automatically converted to the FRF domain, as shown in Fig. 5 and Fig. 6. 


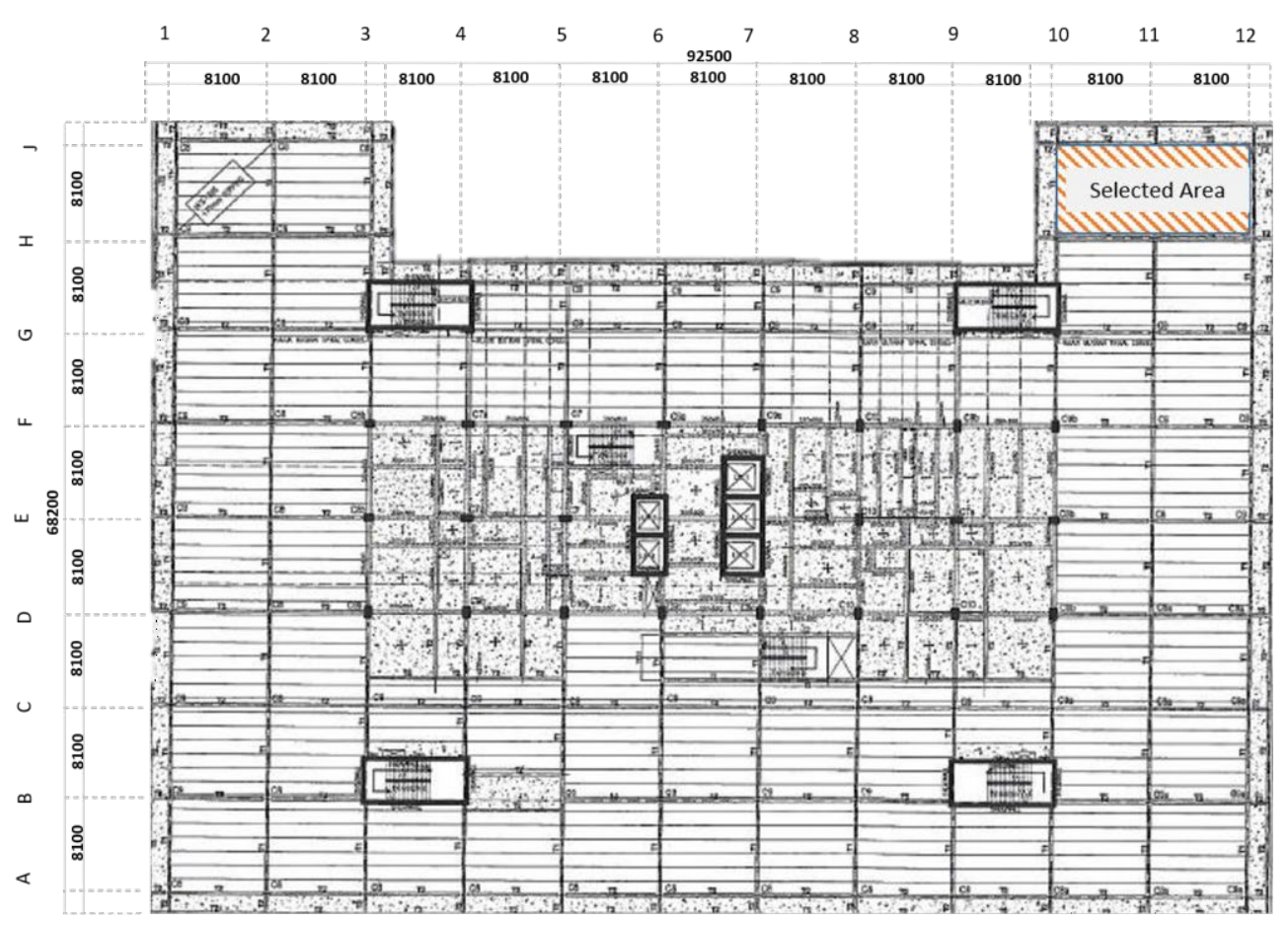

Fig. 1 - Experimental testing area

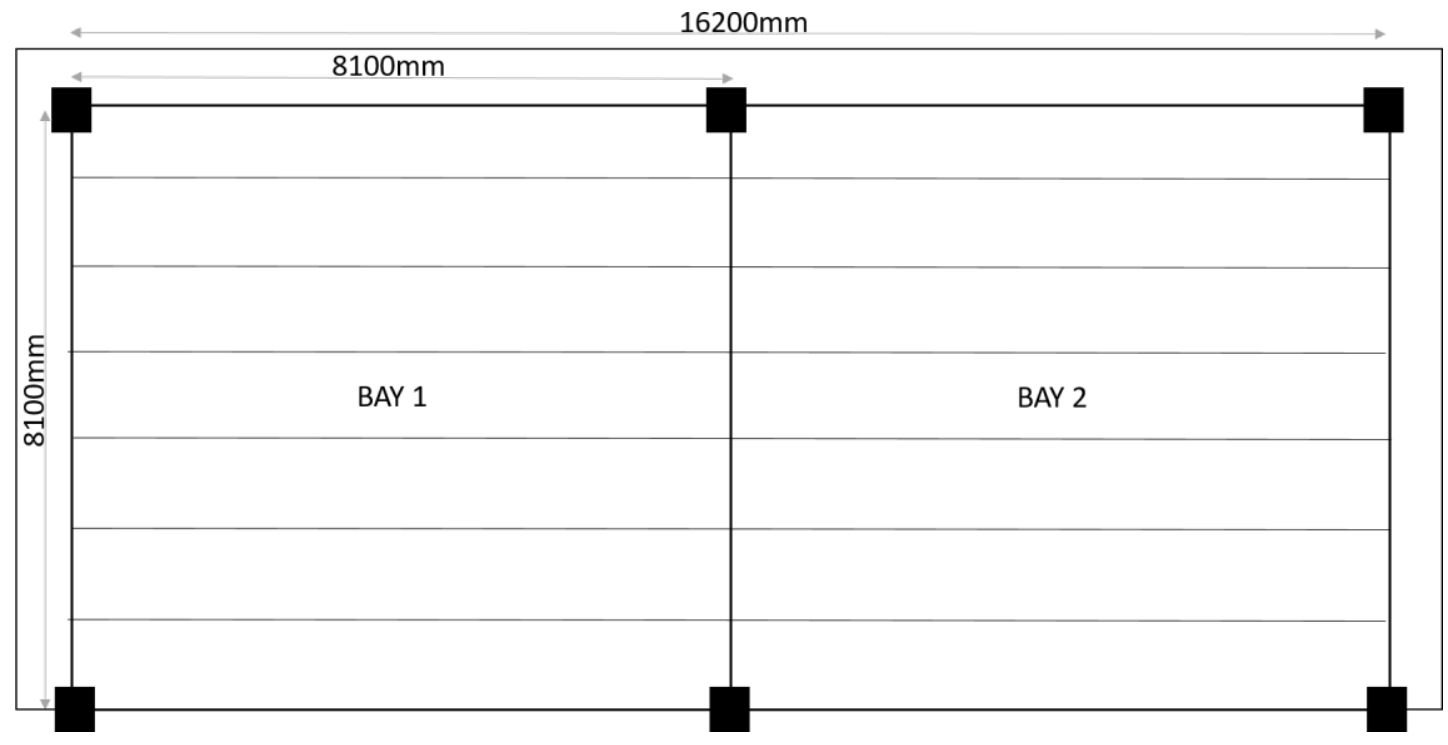

Fig. 2 - Floor detail in the experimental area

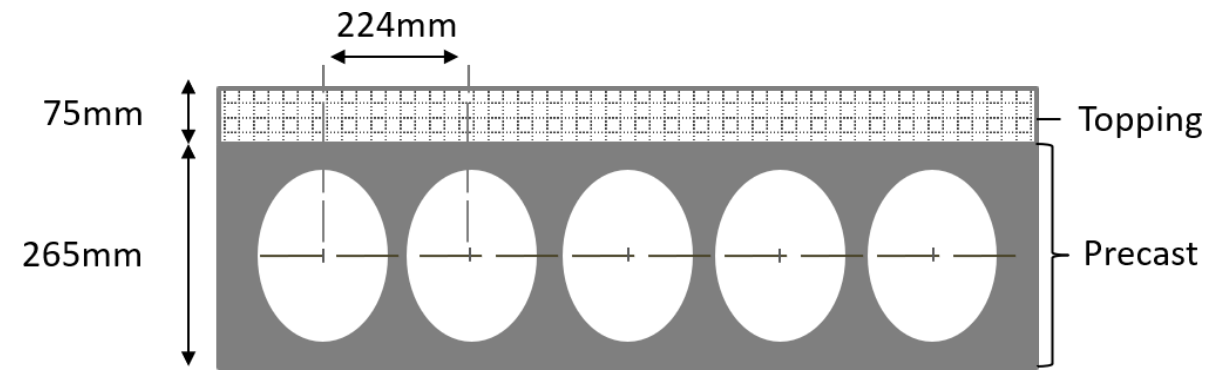

Fig. 3 - Precast cross-section 


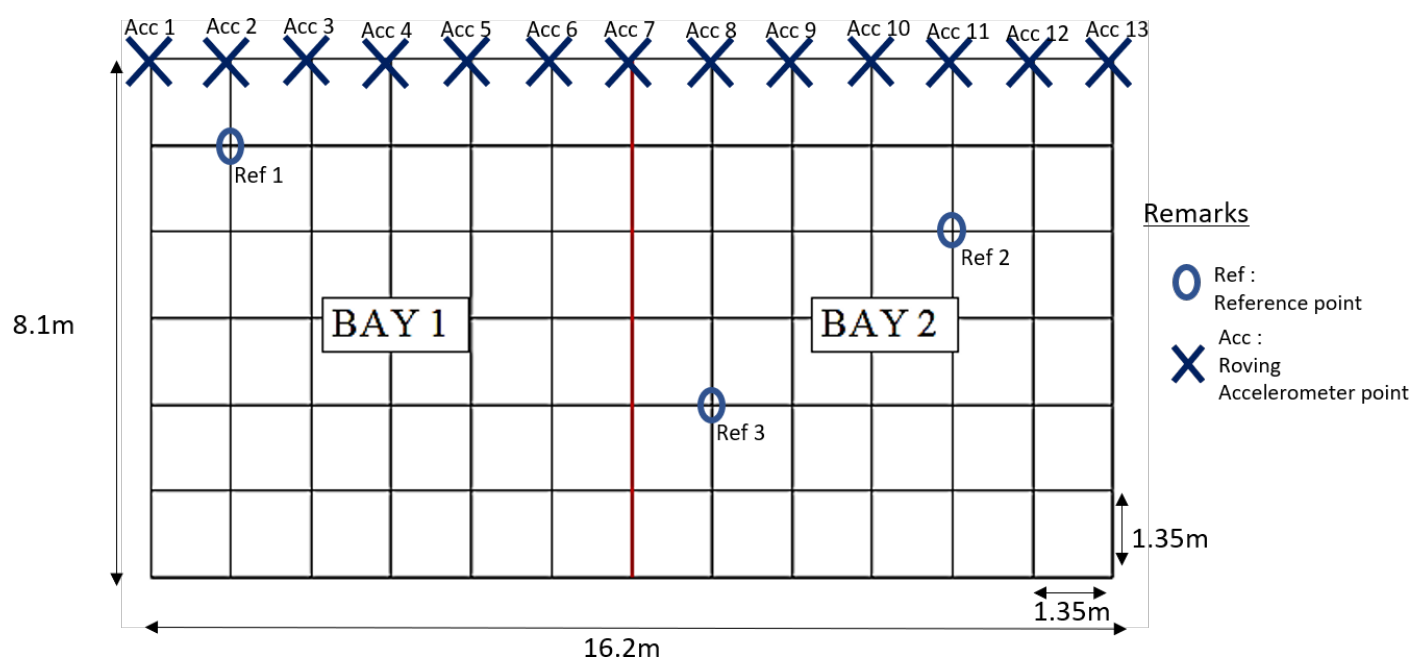

Fig. 4 - Layout for accelerometer and reference point

Table 1 - Acquisition parameters assigned to FRF measurement

\begin{tabular}{lc}
\hline Parameters & Value \\
\hline Sampling rate & $200 \mathrm{~Hz}$ \\
Sampling time & $5 \mathrm{~ms}$ \\
Sample count & 120000 \\
Duration & $10 \mathrm{~min}$ \\
Window & Exponential $(\lambda=0.001)$ \\
\hline
\end{tabular}

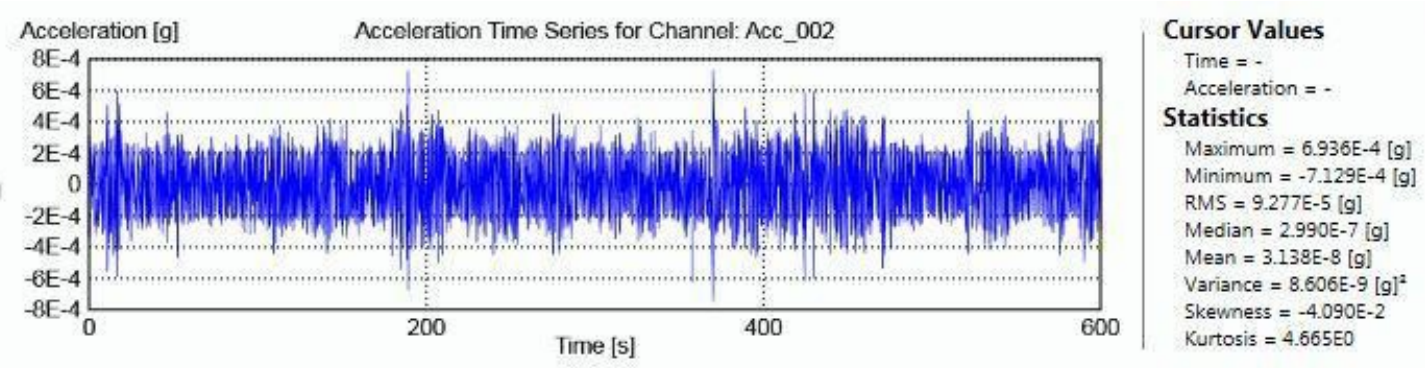

Fig. 5 - Time-domain data

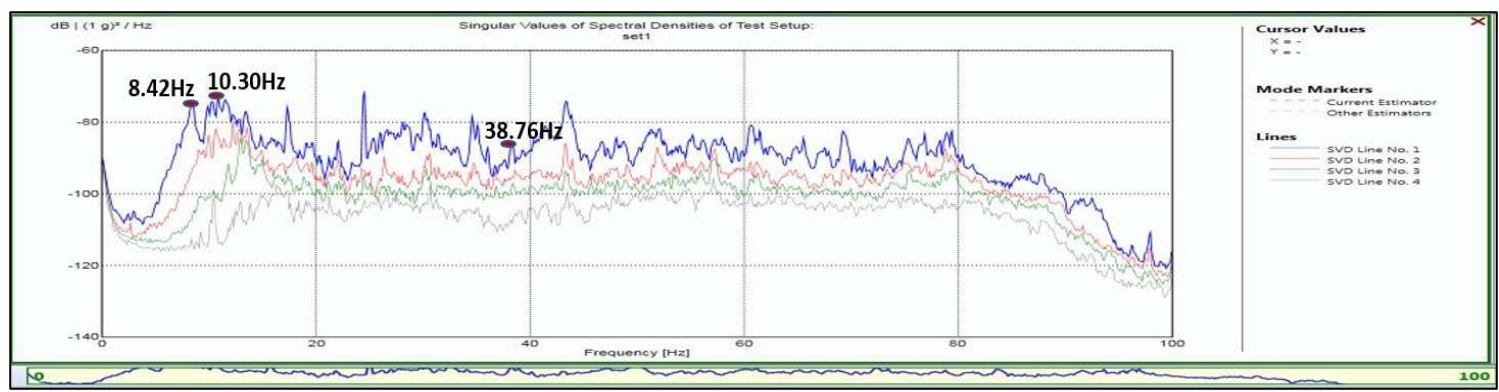

Fig. 6 - Spectral density of test data

The first three natural frequency were recorded at $8.42 \mathrm{~Hz}, 10.30 \mathrm{~Hz}$ and $38.76 \mathrm{~Hz}$, respectively as shown in Fig. 7 . The results show the first natural frequency was below $10 \mathrm{~Hz}$ as recommended from [5], [9], [10]. Thus, it can be concluded that the floor is a low-frequency floor. 
In the EMA, the peak of each natural frequency was determined by corresponding to its mode shape. The mode shape behaviour in the analysis shows the corresponding reaction with natural frequency which confirm the state of each excitation in the PPHCF. Thus, these three mode shape was identified as in Fig. 7.

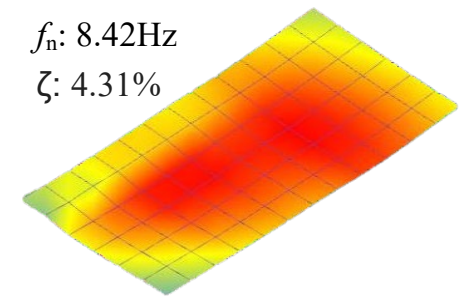

a) Mode 1

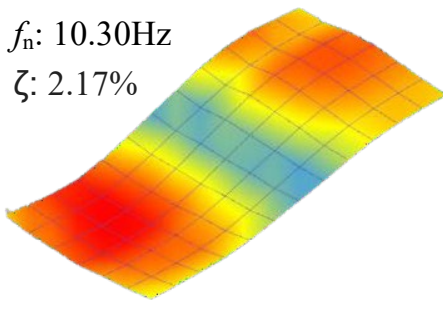

b) Mode 2

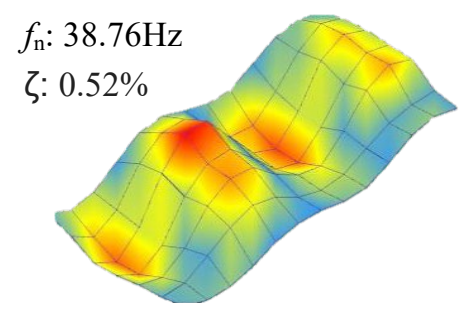

c) Mode 3

Fig. 7 - Vibration response

The damping ratio for the floor structure depleted from $4.31 \%$ to $0.52 \%$ for three mode vibration response. The first mode shows a higher damping. However, the damping ratio of the floor showed a decreased value with a higher frequency. Lower damping can lead to frequent vibration in floors with lighter mass which can affect occupant comfort [11], [12].

\subsection{Vibration Response - Finite Element Analysis (FEA)}

The floor was modelled in SAP 2000 software package and compared with the EMA results to extend the study on the effect of concrete topping thickness on floor vibration behaviour.

The shell element with quadrilateral joints was used in the modelling, as the hollow core section is a nonhomogeneous structural part. Therefore, the shell element that consists of precast components is recommended as it supports all forces and moment. There were three elements involved, namely shell element, beam element and link element. The shell element was assigned with $265 \mathrm{~mm}$ thick on the precast hollow core with C50 concrete strength with concrete topping assigned as shell element with $75 \mathrm{~mm}$ thickness with $\mathrm{C} 35$ concrete strength. On the other hand, the beam element was assigned to I-beams with S335 steel grade. The link element was assigned node by node for concrete grout, bay connection and precast connection with a stiffness value of $2.7602 \times 10^{6} \mathrm{kN} / \mathrm{m}$ as illustrated in Fig. 8 (a). The stiffness value was calculated with $34077 \mathrm{MPa}$ elastic modulus.

The section properties and material of each component were assigned according to the precast features, as shown in Fig. 8(b). The restraint was applied to each PPHCF as a roller (U3), and a column was assigned as fixed (U1, U2, U3, R1, R2, R3). Each node on precast appointed restrain release on U3, which was considered as a grout connection with the beam. The analysis was set up on the XY plane grid with a degree of freedom release (DOF) on U1, R1 and R2 direction. The full-scale view of the floor is shown in Fig. 9.

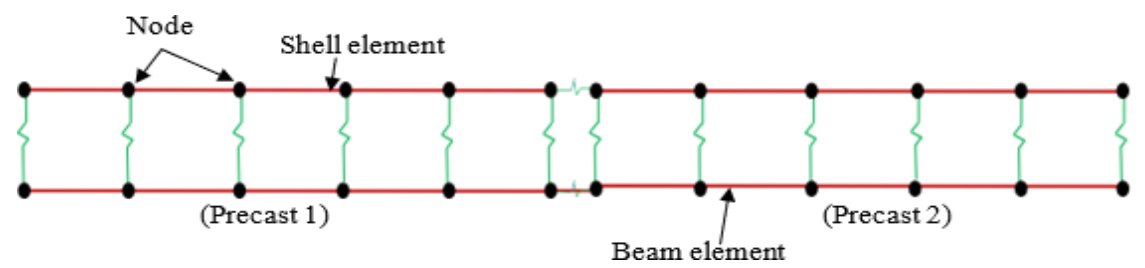

a) Finite element model

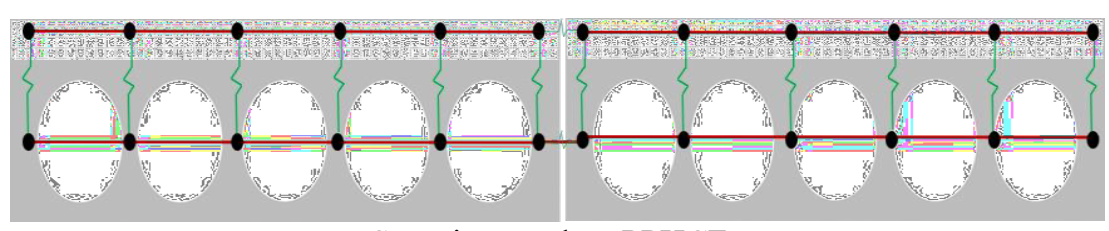

b)

Superimposed on PPHCF

Fig. 8 - Illustrated model 


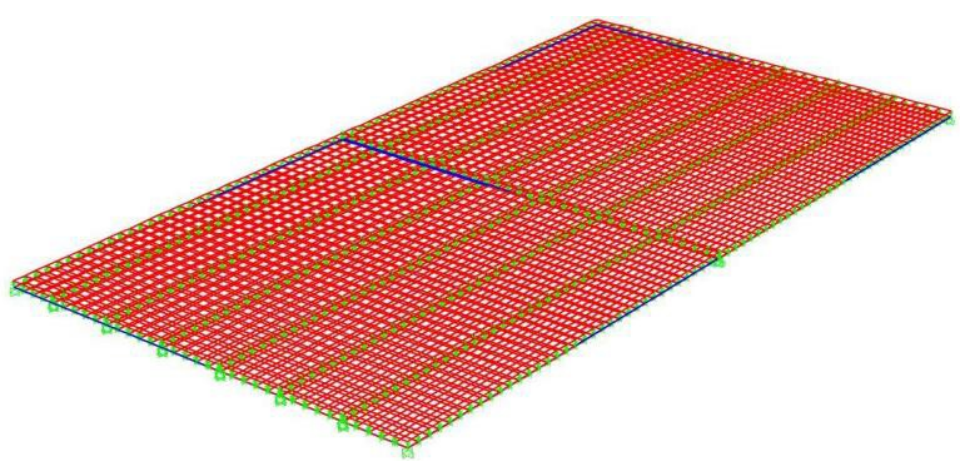

Fig. 9 - Full-scale view model

The results from FEA as depicted in Fig. 10, where the first natural frequency from FEA $(9.17 \mathrm{~Hz})$ was slightly higher than the first natural frequency from EMA $(8.42 \mathrm{~Hz})$. This is due to several factors may effected the EMA results such as noise during the test, which occurred during ongoing construction. Noise from the surrounding such as walking, hammering, piling, and hacking concrete have affected the excitation. However, both results were lower than $10 \mathrm{~Hz}$, the cut-off frequency between low or high frequency floor that suggested from [5], [9], [10] as mentioned before.

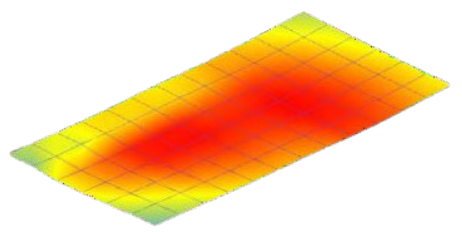

a) $1^{\text {st }}$ mode EMA: $8.42 \mathrm{~Hz}$

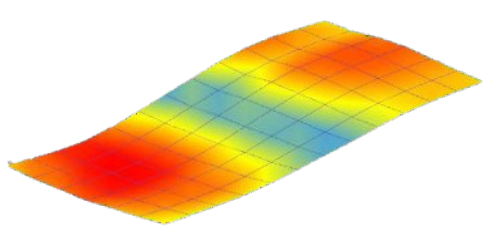

c) $2^{\text {nd }}$ mode EMA: $10.30 \mathrm{~Hz}$

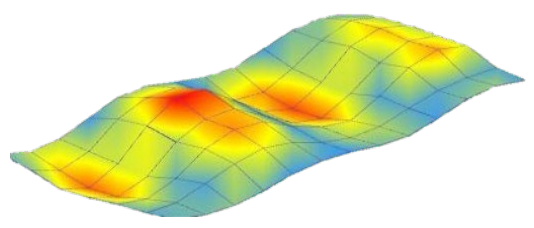

e) $3^{\text {rd }}$ mode EMA: $38.76 \mathrm{~Hz}$

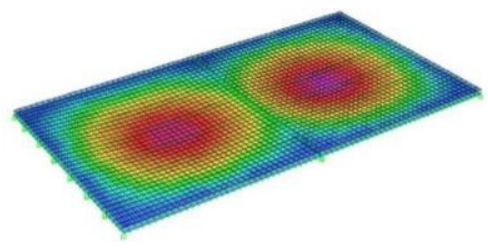

b) $1^{\text {st }}$ mode FEA: $9.17 \mathrm{~Hz}$

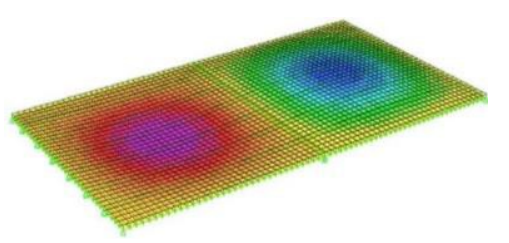

d) $2^{\text {nd }}$ mode FEA: $10.22 \mathrm{~Hz}$

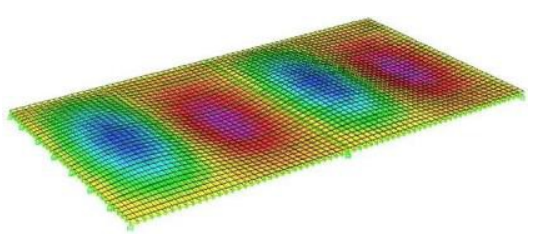

f) $3^{\text {rd }}$ mode FEA: $29.83 \mathrm{~Hz}$

Fig. 10 - Comparative mode shape of FEA and EMA

The EMA mode shape closely resembled the FEA mode shape, with the natural frequency at $8.18 \%$ for the $1 \mathrm{st}$ mode shape while a small error percentage occurred to the 2 nd mode shape at $0.78 \%$ as shown in Table 2 . For the 3 rd mode shape, the natural frequency from EMA was slightly higher than the FEA with an error of 23.04\%. Both EMA and FEA results were below $10 \mathrm{~Hz}$, which can lead the floor to vibrate. The first natural frequency percentage error in the analysis was only $8.18 \%$, which the result is acceptable.

From the EMA and FEA analysis, both results show that the fundamental frequency is below $10 \mathrm{~Hz}$, which is classed as a low-frequency floor as discussed before. According to SCI P354, the concrete society and the concrete centre, general floors as open office space areas with concrete material floors are limited to a cut-off frequency of $10 \mathrm{~Hz}$ [5], [9], [10]. Floor structures that record a fundamental frequency below $10 \mathrm{~Hz}$ are classified as low-frequency floors while those with a fundamental frequency higher than $10 \mathrm{~Hz}$ are classified as high-frequency floors. 
Table 2 - Comparison between EMA and FEA results

\begin{tabular}{lccc}
\hline Mode & 1st mode & 2nd mode & 3rd mode \\
\hline EMA & $8.42 \mathrm{~Hz}$ & $10.30 \mathrm{~Hz}$ & $38.76 \mathrm{~Hz}$ \\
FEA & $9.17 \mathrm{~Hz}$ & $10.22 \mathrm{~Hz}$ & $29.83 \mathrm{~Hz}$ \\
Different (Abs) & 0.75 & 0.08 & 8.93 \\
Error (\%) & 8.18 & 0.78 & 23.04 \\
\hline
\end{tabular}

\subsection{Concrete Topping Thickness}

Concrete topping thickness contributes to added mass, but the layer between the precast concrete and the concrete topping may affect floor vibration due to differing strength and material. Thus, FEA was employed to study the effect of concrete topping thickness on PPHCF.

In SAP2000, the shell element was assigned with similar material and properties as the actual PPHCF with concrete topping. In the FEA, concrete toppings with different levels of thickness to determine the appropriate thickness that responds to a higher frequency. In this study, thickness with a $25 \mathrm{~mm}$ interval starting with $0 \mathrm{~mm}$ until maximum thickness with frequency exceeded $10 \mathrm{~Hz}$ is used to observe the fundamental frequency of each thickness. The fundamental result for each thickness is stated in Table 3.

Table 3 - Fundamental frequency with different concrete topping thicknesses

\begin{tabular}{cccc}
\hline $\begin{array}{c}\text { Thickness } \\
(\mathbf{m m})\end{array}$ & $\begin{array}{c}\text { Fundamental } \\
\text { Frequency }(\mathbf{H z})\end{array}$ & $\begin{array}{c}\text { Thickness } \\
(\mathbf{m m})\end{array}$ & $\begin{array}{c}\text { Fundamental } \\
\text { Frequency (Hz) }\end{array}$ \\
\hline 0 & 10.3 & 200 & 8.85 \\
25 & 9.84 & 225 & 8.99 \\
50 & 9.28 & 250 & 9.16 \\
75 & 9.17 & 275 & 9.37 \\
100 & 8.94 & 300 & 9.6 \\
125 & 8.81 & 325 & 9.84 \\
150 & 8.75 & 350 & 10.09 \\
175 & 8.77 & - & - \\
\hline
\end{tabular}

Table 3 shows the analysis result from $0 \mathrm{~mm}$ to $350 \mathrm{~mm}$ topping thickness. The result showed the naturalfrequency is exceeded $10 \mathrm{~Hz}$ with $350 \mathrm{~mm}$ thickness, however is unrealistic for construction. The impractical thickness was included in the analysis to observe the vibration response behaviour between the PPHCF and concrete topping. The result showed a decrease values in fundamental frequency from $0 \mathrm{~mm}$ until $150 \mathrm{~mm}$ thicknesses. Thickness at $150 \mathrm{~mm}$ is a breakpoint of optimum thickness for the PPHCF system. At this breakpoint, the first natural frequency appeared to be the lowest. The first natural frequency increased after the breakpoint starting at a thickness of $175 \mathrm{~mm}$. The data significantly rose and exceeded $10 \mathrm{~Hz}$ at a thickness of $350 \mathrm{~mm}$.

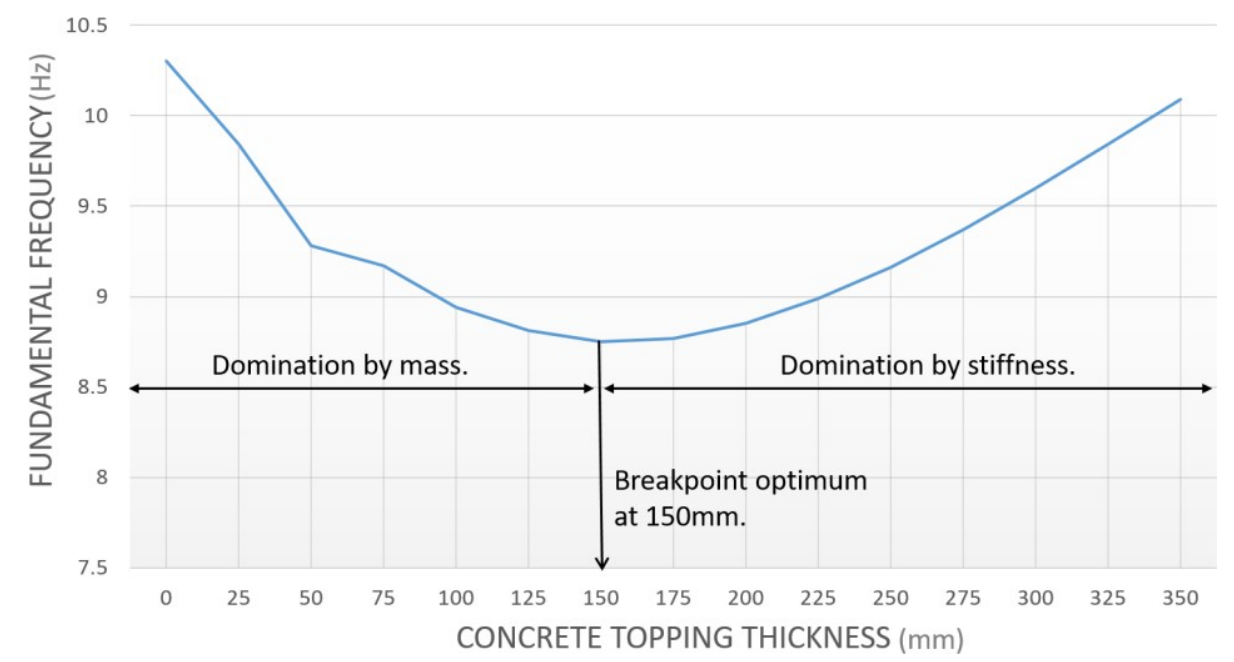

Fig. 11 - Effects of concrete topping thickness effects on precast hollow core 
The vibration responses are different at a point where mass and stiffness react. As shown in Fig. 11, the fundamental frequency decreased under domination by mass. The fundamental frequency is observed to rise under domination by stiffness. When the mass is dominated by the floor system, the low stiffness of the floor system contributes the excessive vibration into the floor.

The behaviour of the structure was effectively affected by mass and stiffness. When the floor structure is dominated by mass, its fundamental frequency decreases. The fundamental frequency of the floor structure will increase when it is dominated by stiffness. As shown in Equation (1), the circular natural frequency shows that mass and stiffness have a significant influence on the fundamental frequency.

$$
f=\sqrt{\frac{k}{m}}
$$

In these equations, $f$ is natural frequency, $\mathrm{k}$ is stiffness and $\mathrm{m}$ is mass. The stiffness and mass dominated equations are shown in Equation (2) and Equation (3).

$$
\begin{gathered}
k=m f^{2} \\
m=\frac{k}{f^{2}}
\end{gathered}
$$

When stiffness dominates, a high mass floor will increase the natural frequency of floors. However, when mass dominates, the natural frequency of floors decreases. The stiffness influenced the reaction between the precast and concrete topping, especially with different concrete strength or material. Albeit the mass was added with additional thickness in the concrete topping, the stiffness between the precast and concrete topping not necessarily to be in stiff condition. After the thickness of concrete topping is reached to its desired mass, the stiffness is dominated and rigid.

The FEA shows that precast concrete without any concrete topping had a higher fundamental frequency compared to precast concrete with concrete topping. However, upon optimum thickness breakpoint, the fundamental frequency increases but stays below $10 \mathrm{~Hz}$. In Fig. 11, a fundamental frequency above $10 \mathrm{~Hz}$ was achieved at a thickness of 350 $\mathrm{mm}$. In terms of construction, it is not economical to build a floor system with greater thickness.

In this research, a concrete topping thickness from $25 \mathrm{~mm}$ to $75 \mathrm{~mm}$ thick was found to be suitable for construction. The first natural frequency for the concrete topping thickness range between $25 \mathrm{~mm}$ to $75 \mathrm{~mm}$ showed it did not fall below $9 \mathrm{~Hz}$. The stated level of frequency can be increased by adding mass from dead loads such as furniture, partition, carpets and tiles.

\subsection{Conclusion}

The objectives of this paper is to study the effect of vibration response with different concrete topping thickness of PPHCF. The EMA was carried out and been validated with FEA in SAP2000 to expand a study with a different concrete topping thickness effect. Three-phase were involved in this study which are in phase 1 is an experimental study on the PPHCF, phase 2 involved a validation using FEM and in phase 3, a parametric study on different concrete toppings. Good agreement was achieved between the EMA and FEA especially on fundamental frequency with only $8.18 \%$ error.

Parametric studies have been performed with different thick of concrete topping thickness with $25 \mathrm{~mm}$ interval. The thickness were modelled from $0 \mathrm{~mm}$ until reach the thickness with natural frequency exceeded $10 \mathrm{~Hz}$ to study it pattern behaviour. The result showed the thickness had reached until 350mm thickness which it unrealistic to construct with $265 \mathrm{~mm}$ precast thickness. However, the purposed of the study is observed the vibration response effect pattern that influenced with mass and stiffness domination. Thus from the discussion, a concrete topping thickness from $25 \mathrm{~mm}$ to $75 \mathrm{~mm}$ thick was found to be suitable for construction.

\section{Acknowledgement}

This research has been supported by the internal grant "Geran Penyelidikan Pascasiswazah" (GPPS) (No: H389) and Research Fund E15501 by the Research Management Centre, Centre for Graduate Studies and the Faculty of Civil Engineering and Built Environment (FKAAB) of Universiti Tun Hussein Onn Malaysia.

\section{References}

[1] Monisha, K. M., \& Srinivasan, G. (2017). Experimental behaviour of prestress hollow core slab, rc hollow core slab and normal rc solid slab. International Journal of Engineering and Technical Research, 4(4), 10901093. 
[2] Johansson, P. (2009). Vibration of Hollow Core Concrete Elements Induced by Walking. Lund Institute of Technology.

[3] Ljunggren, F. (2006). Floor Vibration - Dynamic Properties and Subjective Perception. PhD Thesis, Luleå University of Technology, Sweden.

[4] Wilson A. (1998). Expected Vibration Performance of Wood Floors as Affected by MSR vs.VSR Lumber EDistribution. Master Degree Thesis, Virginia Polytechnic Institute and State University.

[5] Smith, A. L., Hicks, S. J. \& Devine, P. J. (2009). Design of Floors for Vibration: New Approach (Revised Ed). Berkshire: The Steel Construction Institute.

[6] Saidi, I., Haritos, N., Gad, E. F. \& Wilson, J. L. (2006). Floor vibrations due to human excitation - damping perspective. Proc. of Earthquake Engineering Society 2006 Conference, Australian Earthquake Engineering Society.

[7] Abd Ghafar, N. H. \& Sahban, N. M. (2017). Modelling of concrete topping thickness effects on the vibration behaviour for lvl-concrete composite floor (LCC). IOP Conference Series: Materials Science and Engineering, 271, 012096.

[8] Frăţilă, E. \& Kiss, Z. (2016). Finite element analysis of hollow-core slabs. Journal of Applied Engineering Sciences, 6(1), 29-33.

[9] Willford, M. R. \& Young, P. (2006). A Design Guide for Footfall Induced Vibration of Structures. United Kingdom: The Concrete Centre.

[10] Pavic, A. \& Willford, M. R. (2005). Vibration Serviceability of Post-Tensioned Concrete Floors. PostTensioned Concrete Floors Design Handbook, pp 99-107.

[11] Nguyen, H. A. U. (2013). Walking Induced Floor Vibration Design and Control. PhD Thesis, Swinburne University of Technology.

[12] Cao, L., Liu, J., Li, J. \& Zhang, R. (2018). Experimental and analytical studies on the vibration serviceability of long-span prestressed concrete floor. Earthquake Engineering and Engineering Vibration, 17(2), 417-428.

[13] CIS 8 (2007). Design Guide on Precast Concrete Hollow Core Slab. Kuala Lumpur: Construction Industry Development Board.

[14] Mones, R. M. \& Breña, S. F. (2013). Hollow-core slabs with cast-in-place concrete toppings: A study of interfacial shear strength. PCI Journal, 58(3), 124-141.

[15] Liu, F., Battini, J. M., Pacoste, C. \& Granberg, A. (2017). Experimental and numerical dynamic analyses of hollow core concrete floors. Institution of Structures Engineers, 12, 286-297. 